\title{
Study of Interleaved LLC Resonant Converter Operating at Constant Switching Frequency Using SCC
}

\author{
R. Padmavathi \\ Sr. Assistant Professor- Department of EEE, Rajalakshmi Engineering College, Chennai, India. \\ M . Dhivyya Dharshinii \\ PG Student- Department of Power Electronics and Drives
}

\begin{abstract}
The LLC resonant converter operating at constant switching frequency by interleaving technique has been analysed using MATLAB/Simulink. The LLC resonant converter has the advantages of high efficiency, high power density, and low cost. They can be operated at no load condition and at resonance for nominal input voltage. The load sharing problem of LLC resonant converter has been overcome by SCC (Switch Controlled Capacitor). In interleaving technique, all the stages of LLC operate at same switching frequency for the purpose of current ripple cancellation. It has been proposed to reduce the switching losses and voltage ripple by using a PI Filter.
\end{abstract}

Keywords: Switch-controlled capacitor (SCC), LLC resonant converter, MATLAB/SIMULINK.

\section{INTRODUCTION}

The converter which eliminates much of the switching losses associated with fixed frequency by enabling switching at either near - zero voltage or near - zero current is known as resonant converter. The resonant converters can be classified into two types namely, series and parallel resonant converters. The drawback of series resonant converter is that it cannot regulate output at no load condition and output current is high. The disadvantage of parallel resonant converter is circulating current is high and has lower efficiency at reduced loads.

To overcome these drawbacks LLC resonant converter is preferred. The LLC resonant converter can operate at nominal input voltage and at no load conditions. Here we use SCC modulated LLC to overcome the load sharing. Interleaved method is used here is defined as the parallel combination of DC - DC converters with an interleaving difference of $360 / \mathrm{N}$ between the adjacent phases. The purpose of using interleaving method is to reduce the ripple currents at both input and output terminals.

In this paper, the Switch Controlled Capacitor (SCC) is used to control the output voltage by controlling the equivalent capacitance of LLC resonant converter at each stage, thus modulating resonant frequency. As a result of constant switching frequency, the voltage regulation is achieved in individual phases of LLC. In the proposed SCC-LLC topology, a SCC is connected in series with the resonant tank to modulate the equivalent capacitance $\mathrm{C}_{\mathrm{r}}$ thereby controlling resonant frequency. The resonant frequency in turn controls the voltage gain.

\section{LITERATURE REVIEW}

The system proposed in [1] a simple and accurate design methodology for LLC resonant converters, based on a semi empirical approach to model steady-state operation in the "below-resonance" region. This has led to simple yet accurate design-oriented model and to a simple step-by-step design procedure that ensures stable operation at no load, ZVS under all operating conditions. The methodologies based on first harmonic approximation (FHA) analysis are much simpler but due to lack of accuracy especially in below-resonance region it is not used. The system in [2] proposes an approximate analysis of LLC resonant converter with capacitive filter operating above and below resonance. An equivalent $\mathrm{AC}$ resistance model of the rectifier valid for discontinuous as well as continuous conduction modes is proposed. The DC voltage conversion ratio is then obtained using the fundamental harmonic approximation analysis method. Here Fundamental Harmonic Analysis method has been used. Here LLC can operate with wide load range and can achieve step-up as well as step-down voltage conversion. Since it is applicable to off-line converters it has relatively large DC holdup and output capacitor need to provide output voltage support in case of line fault of light load to full load transients. This reduces the power density and has drawback of alleviating fast voltage control. The project in [3] proposed Simulation and Implementation of High Gain Interleaved Boost Converter for Fuel cell applications. For designing high efficiency fuel cell power systems, a suitable DC-DC converter is required. Among the various topologies, 
interleaved converters using switched capacitor are considered as a better solution for fuel cell systems due to high conversion efficiency. In the proposed interleaved converter, the front end inductors are magnetically cross-coupled to improve the electrical performance and reduce the weight and size. Also, switched capacitors are used to improve the voltage gain of the converter.

\section{PROPOSED SYSTEM}

The system proposed in this paper uses the LLC resonant converter for analysis as in [1], [2] and uses Switch controlled capacitor based on interleaving technology for achieving high voltage gain.

The features of the proposed system are:

- Interleaved LLC resonant DC-DC converter with modulated SCC is used.

- This techniques deals with voltage ripple reduction by using PI filter in the output.

- The load used is a PMDC motor load.

The simple block diagram of interleaved DC-DC converter is shown in Fig 1. Since this paper deals with interleaved technique we use a parallel - parallel combination of LLC resonant converter as shown in the block diagram.

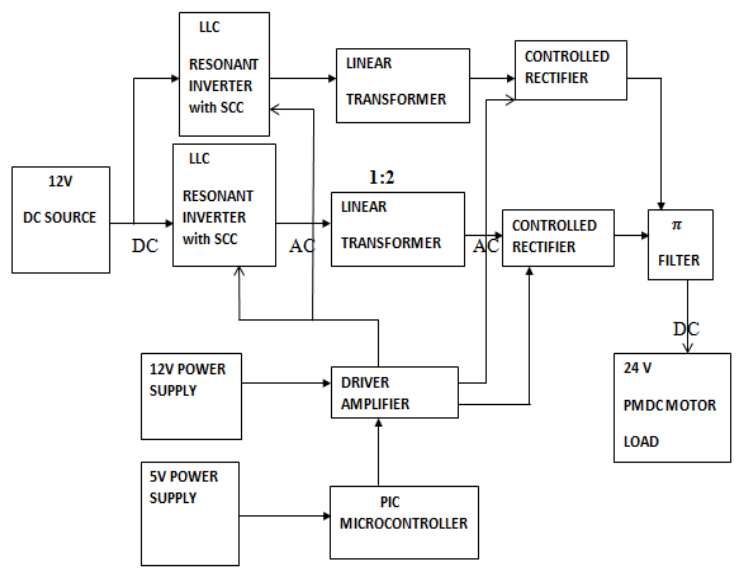

Fig. 1: Block Diagram of proposed system

The Entire system Block Diagram is shown in Fig.1 The Block diagram consists of LLC resonant converter with SCC, Linear Transformer, Controlled Rectifier, PIC controller, PI filter and Driver Amplifier. The input source is a $12 \mathrm{~V} \mathrm{DC}$ source. The DC output from DC source is given to the resonant inverter which converts $\mathrm{DC}$ to $\mathrm{AC}$ and gives the $\mathrm{AC}$ output to the transformer which steps up the voltage. Now the AC output from the transformer is given to a rectifier where it is converted to DC and fed to the PMDC motor.

\section{INTERLEAVED LLC RESONANT CONVERTER}

The LLC resonant converter with interleaving technique is mainly used to achieve high power level. The Fig.2 shows the topology of LLC resonant converter with PI filter feeding R load. The modes of operation of below circuit are explained as follows.

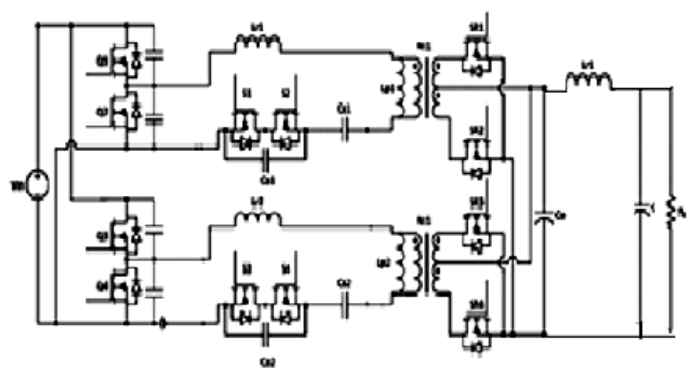

Fig.2: Topology of LLC resonant converter 
In mode 1 , the $\mathrm{Q}_{1}, \mathrm{~S}_{1}$ are in $\mathrm{ON}$ state. The current flows in the direction $\mathrm{Q}_{1}-\mathrm{L}_{1}-\mathrm{L}_{\mathrm{r} 1} \mathrm{C}_{1}-\mathrm{D}_{2}-\mathrm{S}_{1}$. The voltage with positive polarity is given to the primary. Similarly voltage is induced in upper half of secondary. When $\mathrm{SR}_{1}$ is closed current flows through the load. The $\mathrm{Q}_{3}, \mathrm{~S}_{3}$ are $\mathrm{ON}$ and the current flows from $\mathrm{Q}_{3}-\mathrm{L}_{2}-\mathrm{L}_{\mathrm{r} 2}-\mathrm{C}_{2}-\mathrm{D}_{4}-\mathrm{S}_{3}$. Now $\mathrm{S}_{\mathrm{r} 3}$ is closed and current flows through the load.

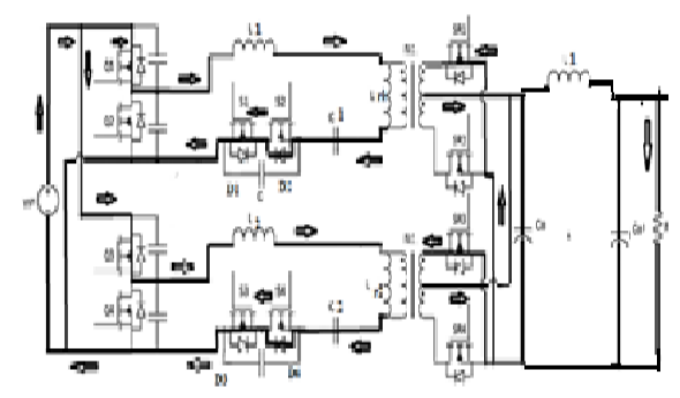

Fig.3: Mode 1 operation of LLC resonant converter

During negative half cycle when $\mathrm{Q}_{2}$ and $\mathrm{S}_{2}$ are in $\mathrm{ON}$ state in mode 2. The current flows in the direction $\mathrm{Q}_{2}-\mathrm{D}_{1}$ $\mathrm{S}_{2}-\mathrm{C}_{1}-\mathrm{L}_{\mathrm{rl}}-\mathrm{L}_{1}$. The voltage across the capacitor is applied to the primary with negative polarity. Similarly voltage is induced in the secondary with negative polarity. Current flows through $\mathrm{SR}_{2}$ and load. The $\mathrm{Q}_{4}$ and $\mathrm{S}_{4}$ are in ON state. The current flows through $\mathrm{Q}_{4}-\mathrm{D}_{2}-\mathrm{S}_{4}-\mathrm{L}_{\mathrm{r} 2}-\mathrm{L}_{2}$. The $\mathrm{S}_{\mathrm{r} 4}$ is closed and current flows through the load.

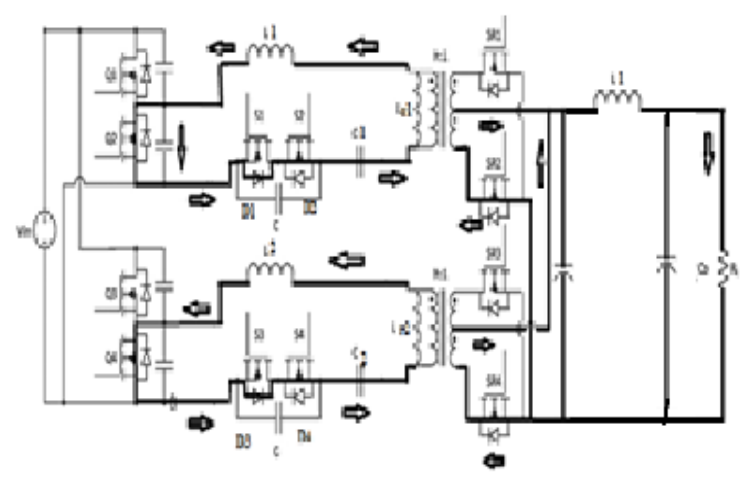

Fig .4: Mode 2 operation of LLC resonant converter

\section{THEORETICAL ANALYSIS}

The output voltage of the proposed LLC resonant converter can be increased by interleaving technique.

The resonant frequency is given by

$$
\mathrm{f}_{\mathrm{r}}=\frac{\mathrm{t}}{\sin 2 \mathrm{en}} \quad \ldots .1
$$

The equivalent capacitance of SCC is given by

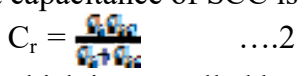

The Capacitor which is controlled by switches $\mathrm{S}_{1}$ and $\quad \mathrm{S}_{2}$

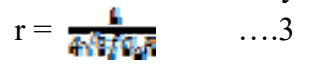

The inductance value is calculated using

$$
\mathrm{L}_{\mathrm{s}}=\frac{\mathrm{A}-\mathrm{Di}}{\mathrm{H}} \quad \ldots .4
$$

The torque equation for PMDC motor is

$$
\mathrm{T}=\mathrm{K} \phi \mathrm{I}_{\mathrm{a}} \quad \ldots .5
$$

$\mathrm{f}_{\mathrm{r}}$ is the resonant frequency, $\mathrm{r}$ is the ripple factor, $\mathrm{C}_{\mathrm{sc}}$ is the value of equivalent capacitance which is calculated Series capacitor $\mathrm{C}_{\mathrm{s}}$ and Resonant capacitor $\mathrm{C}_{\mathrm{r}}$. The value of Capacitor which is controlled by switches $S_{1}$ and $S_{2}$ is calculated from ripple factor. The value of series inductance of resonant converter is 
calculated using equation 4. The torque of PMDC motor is calculated using equation 5 and the speed is obtained from the torque value calculated.

\section{VOLTAGE RIPPLE REDUCTION}

$12 \mathrm{~V}$ is given as input and the ouput voltage obtained is $24 \mathrm{~V}$. The interleaved topology is frequently used to achieve low ripple current and to achieve high efficiency compared to other existing topologies. Here the LLC resonant converter is connected in parallel with another LLC resonant converter to achieve interleaved topology.

The proposed system of LLC resonant converter with PI filter is shown in Fig 4.1. The input DC supply is given to the LLC resonant inverter where the resonant operation is carried out and the input DC is converted to AC and is given to the transformer. The transformer will step up the voltage and gives it to the rectifier. The rectifier converts AC to DC and supplies to the load connected. $\mathrm{C}$ filter is used in the existing system to reduce the ripples in the output voltage and current. But PI filter reduces more ripples than C filter and hence we go for the proposed system as shown in Fig 5.

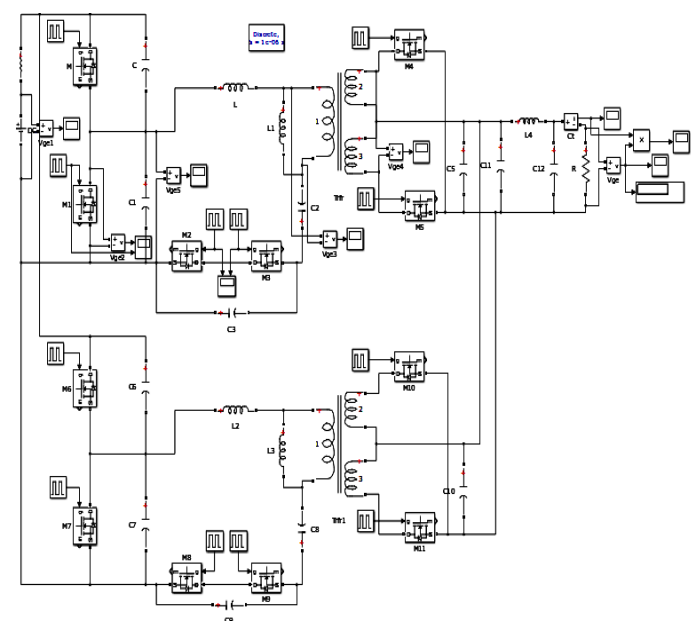

Fig.5: Simulation circuit of LLC resonant converter with R Load

The DC input voltage is boosted up and is supplied to the load. The ripples reduced by $\mathrm{C}$ filter are less compared to PI filter. So, C filter is replaced by PI filter in the proposed system.

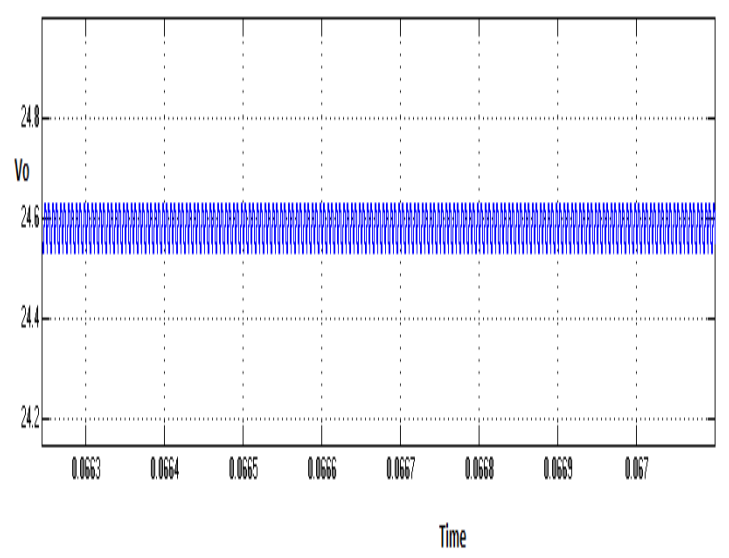

Fig.6: Voltage Ripples with C filter with R load

The simulation results of LLC resonant converter with PI filter connected to an R load are given. The voltage ripples with R load connected to C filter and PI filter is shown in Fig 6 and Fig 7. 


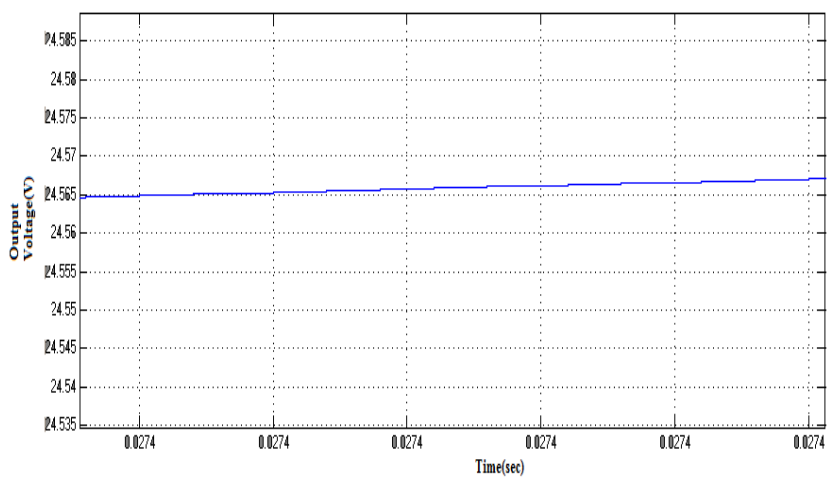

Fig.7: Output voltage of PI filter with R Load

The interleaving technique requires all the stages of LLC resonant converter to operate at constant switching frequency for the cancellation of ripple current. An SCC is connected in series with the resonant tank in order to modulate the equivalent resonant capacitance $\left(\mathrm{C}_{\mathrm{r}}\right)$ and thus controlling resonant frequency. The centre tapped full wave rectifier mainly replaces four diodes by two diodes. The resonant frequency in turn controls the voltage gain. About $99 \%$ of ripples get reduced by PI filter and the output will be obtained as shown in the waveform. The advantage of using PMDC motor is that, there is no need for field excitation and is cost effective compared to other motors.

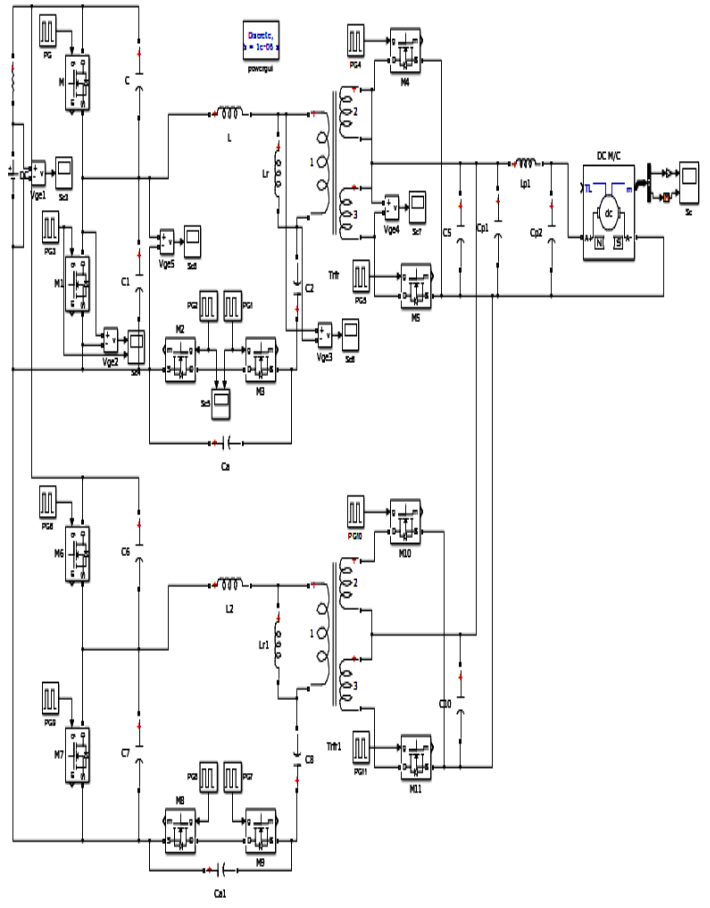

Fig.8: Open loop simulation of LLC resonant converter feeding PMDC Motor

The speed and torque characteristics of LLC resonant converter with motor load for open loop circuit are shown in the Fig 9. The value of speed obtained for open loop LLC resonant Converter is 209 rpm and the torque value obtained is $1.32 \mathrm{Nm}$. 

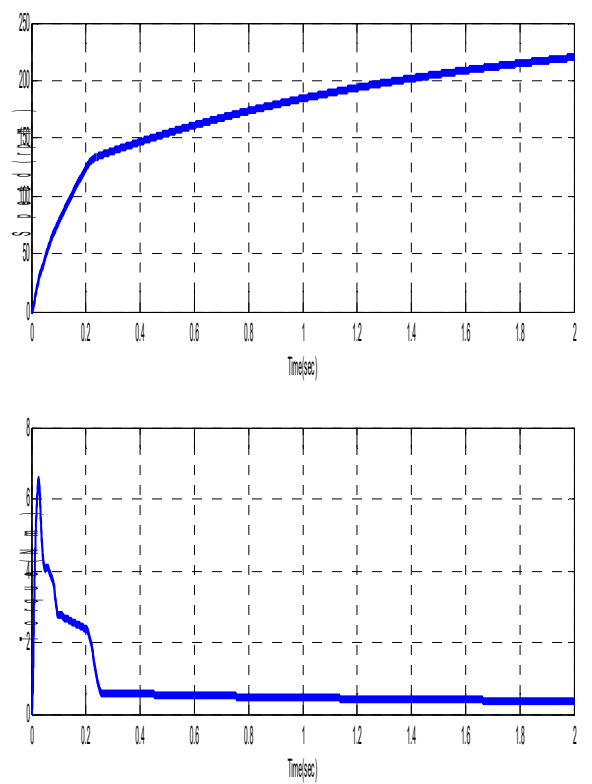

Fig9 Speed and Torque characteristics of PMDC motor

The comparison of LLC resonant converter with C filter and PI filter is given in the table below.

\begin{tabular}{|l|c|c|}
\hline PARAMETERS & $\begin{array}{c}\text { EXISTING } \\
\text { C FILTER }\end{array}$ & $\begin{array}{c}\text { PROPOSED } \\
\text { PI FILTER }\end{array}$ \\
\hline Input voltage & $12 \mathrm{~V}$ & $12 \mathrm{~V}$ \\
\hline Output voltage & $24 \mathrm{~V}$ & $24 \mathrm{~V}$ \\
\hline & & \\
Output current & $1.2 \mathrm{~A}$ & $1.2 \mathrm{~A}$ \\
\hline & & \\
Output power & $30 \mathrm{~W}$ & $30 \mathrm{~W}$ \\
\hline & & \\
Ripple & $9 \%$ & $0.1 \%$ \\
\hline
\end{tabular}

TABLE.1: System comparisons of C Filter and PI Filter for Proposed LLC Resonant converter with Motor Load

\section{CONCLUSION}

The simulation of LLC resonant converter with PI filter fed to PMDC motor was successfully carried out using MATLAB/Simulink software and output waveforms were observed. The voltage ripples are reduced by using PI filter. The voltage regulation will be achieved as the result of individual LLC phases which will have same switching frequency at all the phases. The comparison has been carried out between existing system and proposed system. From the analysis it is clear that proposed system is advantageous over the existing system, and it is used to drive a PMDC motor.

\section{REFERENCES}

[1] Adranga. C, De Simone and S Pini. C (2008) "A design methodology For LLC resonant converters based on inspection of resonant tank currents" STMicroelectronics IEEE 2008. 
[2] Alexander Abramovitz, Gregory Ivensky and Svetlana Bronshtein,(2011,November) “Approximate Analysis of Resonant LLC DCDC Converter" IEEE Transcations on Power Electronics, VOL. 26.

[3] Anitha. R, Bhavani. M, Mahalakshmi. S, Dr. Seyezhai. R (2013 July) "Simulation and Implementation of High Gain Interleaved Boost Converter For Fuel cell application" International Journal of Innovative Research in Computer and Communication Engineering Vol. 1, Issue 5.

[4] Alpha Zhang. J, Bo Yang, Fred Lee. C, Guisong Huang and Renyuang Cheng (2006, July) "LLC Resonant Converter for Front End DC/DC Conversion" National Science Foundation under Award Number EEC-9731677.

[5] Bing Lu, Fred Lee. C, Jacobus van Wyk. D, Wenduo Liu (2006, July) "Optimal Design Methodology for LLC Resonant Converter" Centre of Power Electronics Systems.

[6] Emil Audisian, Frank Chen, Haibing Hu, Issac Bataresh, John Shen, Utsav Somani, Xiang Fang (2013, May) "Efficiency-Oriented Optimal Design of The LLC Resonant Converter Based on Peak Gain Placement" IEEE Transaction on Power Electronics, VOL.28, NO. 5.

[7] Haibing Hu, Issac Bataresh, John Shen. Z, Xiang Fang (2012, April) "Operation Mode Analysis and Peak Gain Approximation of the LLC Resonant Converter" IEEE Transaction on Power Electronics, VOL. 27, NO. 4.

[8] Jimmy Liu, Kin Lap Wong, John Mookken. Scott Alle (2009, November)"Performance Evaluations of Hard-Switching Interleaved DC/DC Boost Converter with New Generation Silicon Carbide MOSFETs" SiC Application Engineering. IEEE.

[9] Mounica Ganta, Pallam Reddy Nirupa, Dr.Seyezhai. R, Thimmadi Akshita (2012, April) "Simple and Efficient Implementation of Two-Phase Interleaved Boost Converter for Renewable Energy Source" International Journal of Emerging Technology and Advanced Engineering, ISSN 2250-2459, Volume 2, Issue 4

[10] Ruey - Hsun Liang, Shin-Ming, Yie-Tone Chen (2012, January)“Analysis and Design of a Zero-Voltage-Switching and Zero-CurrentSwitching Interleaved Boost Converter” IEEE Transaction on Power Electronics, Vol 27,No1 